\title{
Advances in Synthetic Biology and Metabolic Engineering in the Production of Biofuel
}

\author{
Sami El Khatib* and Nejma Abou Yassine \\ Lebanese International University, Department of Biological Sciences, Bekaa Campus, \\ Khiyara - West Bekaa, Lebanon \\ *Corresponding author
}

\section{A B S T R A C T}

Keywords

Fossil fuels, biotechnology, lignocellulosic residues

Article Info

Accepted:

20 August 2019

Available Online:

10 September 2019
Biofuels are renewable fuels are made from biomass materials, produced through biological processes such as anaerobic digestion or agriculture, rather than the fuels produced through geological processes such as coal and petroleum. Biofuels primarily include ethanol and biodiesel and have numerous advantages such as lower carbon emissions over fossil fuels. Ethanol and biodiesel are usually blended with petroleum fuels (gasoline and diesel fuel), but they can also be used on their own. Using ethanol or biodiesel means less gasoline and diesel fuel is burned, which can reduce the amount of crude oil imported from other countries. Ethanol and biodiesel are also cleanerburning fuels than pure gasoline and diesel fuel. Technologies to produce biodiesel from waste oil and animal fat feedstock are technically mature and provided 6-8\% of all biofuel output in the last decade. However, production of novel advanced biofuels from other technologies is still modest, with progress needed to improve technology readiness. These technologies are important nevertheless as they can utilise feedstock with high availability and limited other uses.

\section{Introduction}

Fossil fuels are considered the major sources of energy that human beings depend on, but there are many problems the world is facing related to this dependence. The high emission of greenhouse gases due to excessive fossil fuel combustion and the resulting damages on the environment, the continuously fluctuating and high fuel prices and the instability of fossil fuel supplies due to their nonrenewability, are major problems that increased people's interest in searching for renewable energy resources. This has led them to produce biofuels from renewable resources with lower energy needs and less polluting effects depending on the field of "white biotechnology", a branch of biotechnology that embraces the bio- production of fuels and chemicals from renewable sources. The 
concept of biofuels was first conceived in the 1970s when the world faced a large-scale oil crisis. Recent advances in synthetic biology, metabolic engineering, and systems biology, have generated a renewed interest in the production of biofuels (Dellomonaco, 2010).

This chapter provides an overview of biofuel production process emphasizing the two major types of biofuels, bioethanol and biodiesel. The main features and characteristics will be discussed taking into consideration their sources, their major characteristics and the different methods of their synthesis.

\section{Biofuel Production}

A biofuel is any type of liquid or gaseous fuel that can be produced from biomass substrates and that can be used as a partial substitute for fossil fuels (Giampietro, 2008).

Biofuels can be produced from many sources. These include agricultural lignocellulosic residues, edible and non-edible crops, and waste streams (e.g. bagasse from sugar manufacture, industrial by-products) (Dellomonaco, 2010).

Land plants, which capture solar energy, make carbon molecules and give up the molecules in a transformable state (Wackett, 2008). These transformable molecules include glucose, fructose and starches and thus, commonly used plants are sugarcane, sugar beets, corn, barley and wheat and these are the primary feed stocks currently used for bioconversion to ethanol (Wackett, 2008; Dellomonaco, 2010). Other crops such as oil seed crops (soybean, oil palm, sunflower) are mainly composed of various triacylglycerols (TAGs), molecules consisting of three fatty acids chains (usually 18- or 16-C long) esterified to glycerol and they are used to produce biodiesel (Dellomonaco, 2010). As these plants are edible, they pose a food security issue.
Therefore, current research is being focused on the use of cellulosic or more accurately lignocellulosic biomass which generally consists of $\sim 25 \%$ lignin and $\sim 75 \%$ carbohydrate polymers (cellulose and hemicellulose) and it is the largest known renewable carbohydrate source on earth (Wackett, 2008; Dellomonaco, 2010). Recent data indicate that utilizing microalgae could be a new revolution in the production of biofuels.

There is a variety of both liquid and gaseous biofuels that are being produced. These include alcohols (ethanol- methanol), alcohol esters of fatty acids (biodiesel), ethers (methyl-t- butyl ether - dimethyl ether), hydrocarbons (isoprenoid compounds, alkanes - alkenes) and hydrogen gas (Wackett, 2008). The two global biomass-based liquid transportation fuels that might replace gasoline and diesel fuel are ethanol and biodiesel (Kralova and Sjöblom, 2010). The next sections will focus on these two bio fuels.

\section{Bioethanol}

Bioethanol is the most widely used liquid biofuel; in 2004 worldwide production of bioethanol reached 41 billion liters. The largest producers in the world are Brazil (37\%), the United States (33\%), and Asia (14\%) (Carere, 2008). The term bio ethanol is defined as an ethyl alcohol or ethanol (CH3$\mathrm{CH} 2-\mathrm{OH}$ ) produced via biological processes that convert biomass into bio ethanol through biochemical processes such as hydrolysis and microbiological fermentation, rather than ethylene hydration and gasification (Deenanath, 2012).

\section{Sources}

There are many sources that can be used for the production of bio ethanol. They can be classified into first, second, and third generation feed stocks, depending on the 
sources of carbohydrate materials. Firstgeneration feed stocks are starchy materials including cereal grains and sucrose-rich materials such as sugar cane. Secondgeneration feed stocks are predominantly lignocellulosic materials such as wheat straw, switch grass and corncobs, to name a few. Third generation feed stocks are microalgae biomass such as seaweed (Deenanath, 2012).

\section{Characteristics}

Ethanol contains $35 \%$ oxygen that may result in a more complete combustion of fuel and thus reduces emission of carbon dioxide, methane nitrous oxide (Chandel, 2007).

Ethanol is an excellent motor fuel. It has a motor octane number of 98 which exceeds that of gasoline (octane number of 80). It also has a lower vapor pressure than gasoline, which results in lower evaporative emissions. Ethanol's flammability in air is also lower than that of gasoline which reduces the number and severity of vehicle fires (Goldemberg, 2008).

Ethanol represents closed carbon dioxide cycle because after burning of ethanol, the released carbon dioxide is recycled back into plant material because plants use $\mathrm{CO}_{2}$ to synthesize cellulose during photosynthesis cycle and since it uses energy from renewable energy sources, no net carbon dioxide is added to the atmosphere (Chandel, 2007). This cycle is shown in Figure 1.

Bioethanol has some disadvantages. First, combustion of bioethanol when blended with petrol releases formaldehyde and acetaldehyde, which are toxic to humans, and second, the use of agricultural products such as cereal grains will limit food and feed reserves in developing countries, leading to possible food crisis (Deenanath, 2012).

\section{Synthesis}

Bioethanol is being synthesized widely from lignocellulosic biomass. Lignocellulose is made up of cellulose, hemicellulose and lignin. Cellulose is a linear, crystalline homopolymer with repeating units of glucose bound together via beta-glucosidic linkages. Hemi-cellulose consists of short, linear and highly branched chains of sugars consisting of many sugars (heteropolymer) including Dxylose, D-glucose, D-galactose, D-mannose and L-arabinose (Chandel, 2007).

The process involves several steps: pretreatment, hydrolysis, fermentation and product separation/ distillation. Native lignocellulosic biomass is extremely resistant to enzymatic digestion due to the presence of lignin.

In order to enhance digestibility, several methods have been employed, and the most one used is thermochemical processing (Chandel, 2007).

Hydrolysis could be done using chemical or biological procedures. Here, biological ones will be considered. In this process, celluloses and hemi-celluloses are broken down by means of enzymes into their monosaccharaides in order to be fermented. Bacteria and fungi are good sources of cellulases and hemi- cellulases.

Hydrolysis could be separated from fermentation (Separate hydrolysis and fermentation (SHF)), both processes could be performed simultaneously in the same vessel (Simultaneous saccharification and fermentation (SSF)) or could be conducted in the same microorganism in a process called direct microbial conversion (DMC) (Chandel, 2007). 
In SHF, hydrolysis is first conducted by the use of enzymes and then the product is incubated with the fermentative micoorganisms in order to produce ethanol (Figure 2). This enables enzymes to operate at higher temperature for increased performance and fermentation organisms to operate at moderate temperatures, optimizing the utilization of sugars (Chandel, 2007).

SSF includes the co-fermentation of multiple sugar substrates where cellulase enzymes and fermenting microbes arecombinded in a single vessel. This enabled a one-step process of sugar production and fermentation into ethanol (Figure 3). Simultaneous saccharification of both carbon polymers: cellulose to glucose and hemicellulose to xylose and arabinose, and fermentation will be carried out by recombinant yeast or the organism which has the ability to utilize both C5 and C6 sugars (Chandel, 2007).

In DMC, both ethanol and all required enzymes are produced by a single microorganism. This process may help reduce the cost of bioethanol production by circumventing the step of enzyme preparation, but it's not widely used since there is no organism available that can produce cellulases or other cell wall degrading enzymes in conjunction with ethanol with a high yield. Studies found that several strains of Fusarium oxysporum have the potential for converting D-xylose and cellulose to ethanol in a one-step process.

The advantages of this organism are the in situ cellulase production and cellulose fermentation, pentose fermentation, and the tolerance of sugars and ethanol. The main disadvantage of $F$. oxysporum is its slow conversion rate of sugars to ethanol as compared to yeast (Chandel, 2007).

\section{Biodiesel}

Biodiesel has been gaining worldwide popularity as an alternative energy source. Biodiesel is defined as "mono alkyl esters of fatty acids derived from vegetable oil or animal fats".

These naturally occurring oils and fats are composed mainly of triglycerides which have a great similarity to petroleum derived diesel and hence the name biodiesel (Bajpai and Tyagi, 2006).

\section{Sources}

A variety of biolipids can be used to produce biodiesel and these include (Kralova and Sjöblom, 2010):

Virgin vegetable oil feedstock; rapeseed and soybean oils are most commonly used, though other crops such as mustard, palm oil, sunflower, hemp, and even algae show promise

Waste vegetable oil

Animal fats including tallow, lard, and yellow grease

Nonedible oils such as jatropha, neem oil, castor oil, tall oil, etc.

Engineering microbes (E. coli) in order to produce free fatty acids (FFA) which are nonesterified carboxylic acids containing acyl chains ranging from four (butyric) to 18 (stearic) carbons and produced by enzymatic cleavage of lipids and acyl-thioesters in the cell (Lennen and Pfleger, 2012).

Biodiesel production from different sources is given in Table 1. 


\section{Characteristics}

The oxygen content of a fuel improves its combustion efficiency due to an increase in the homogeneity of oxygen with the fuel during combustion. The higher oxygen content encourages more complete combustion. Neat biodiesel generally contains $10-11 \%$ oxygen whereas petroleum diesel contains almost no oxygen. Because of this, the combustion efficiency of biodiesel is higher than that of petrodiesel (Kralova and Sjöblom, 2010). Moreover, the combustion of biodiesel provides over a $90 \%$ reduction in total unburned hydrocarbons, a 75-90\% reduction in polycyclic aromatic hydrocarbons and significant reductions in particulates and carbon monoxide than the combustion of petroleum diesel fuel (Figure 4).

Biodiesel is also safe, renewable, non-toxic, biodegradable in water, free of sulfur compounds, has a high flash point $\left(>130^{\circ} \mathrm{C}\right)$ and better lubricant properties than diesel (Bernal, 2012).

The major disadvantages of biodiesel are its higher viscosity, lower energy content, higher cloud point and pour point, higher nitrogen oxide (NOx) emissions, lower engine speed and power, high price, and higher engine wear. Higher viscosity results in fuel pumping difficulty. Taking into account the higher production value of biodiesel as compared to petrodiesel raises its price. Biodiesel has a higher cloud point and pour point compared to conventional diesel.

Neat biodiesel and biodiesel blends increase nitrogen oxide (NOx) emissions compared with petroleum-based diesel fuel used in an unmodified diesel engine. Biodiesels on average decrease power by 5\% compared to diesel at rated loads (Kralova and Sjöblom, 2010).

\section{Synthesis}

Biodiesel is obtained by transesterifying triglycerides with methanol. Methanol is the preferred alcohol for obtaining biodiesel because it is the cheapest and the shortest chain alcohol, more reactive with oil and the basic catalyst is easily soluble in it (Kralova and Sjöblom, 2010; Bajpai and Tyagi, 2006). Biodiesel produced by transesterification reactions can be alkali catalyzed, acid catalyzed, or enzyme catalyzed (Kralova and Sjöblom, 2010). Base catalysts are more effective than acid catalysts and enzymes for several reasons:

It involves low temperature and pressure. It yields high conversion (98\%) with minimal side reactions and reaction time.

It allows a direct conversion into biodiesel with no intermediate compounds. It requires simple construction materials (Kralova and Sjöblom, 2010).

\section{Base Catalyzed Synthesis}

The base-catalyzed production of biodiesel generally occurs using the following steps: mixing of alcohol and catalyst, transesterification reaction, separation, biodiesel washing, alcohol removal, glycerin neutralization and assessing product quality (Kralova and Sjöblom, 2010). Transesterification is also called alcoholysis and occurs according to Equation 1.

The protocol involves the dissolution of the catalyst in methanol by vigorous stirring, and mixing the resulting alcohol/catalyst solution with the vegetable oil to give two liquid phases (biodiesel and glycerol) with high yields (>90\%) after several hours at $65-90{ }^{\circ} \mathrm{C}$ (Bernal, 2012). 
Table.1 Production Sources of Biodiesel in Different Countries (Bajpai and Tyagi, 2006).

\begin{tabular}{|l|l|}
\hline Country & Source of biodiesel \\
\hline USA & Soybean \\
\hline Brazil & Soybean \\
\hline Europe & Rapeseed oil (>80\%) and sunflower oil \\
\hline Spain & Linseed and olive oil \\
\hline France & Sunflower oil \\
\hline Italy & Sunflower oil \\
\hline Ireland & Animals fat, beef tallow \\
\hline Indonesia & Palm oil \\
\hline Malaysia & Palm oil \\
\hline Australia & Animals fat, beef tallow and rapeseed oil \\
\hline China & Guang pi \\
\hline Germany & Rapeseed oil \\
\hline Canada & Vegetable oil, animal fat \\
\hline
\end{tabular}

Fig.1 Ethanol begins its life as carbon stored in biomass; this is converted to ethanol, which is burnt as fuel that emits water and carbon dioxide. Photosynthesis converts the carbon back into biomass, to be used in the next cycle of ethanol production.

\section{$\mathrm{CO}_{2}$-CYCLE OF BIOETHANOL}

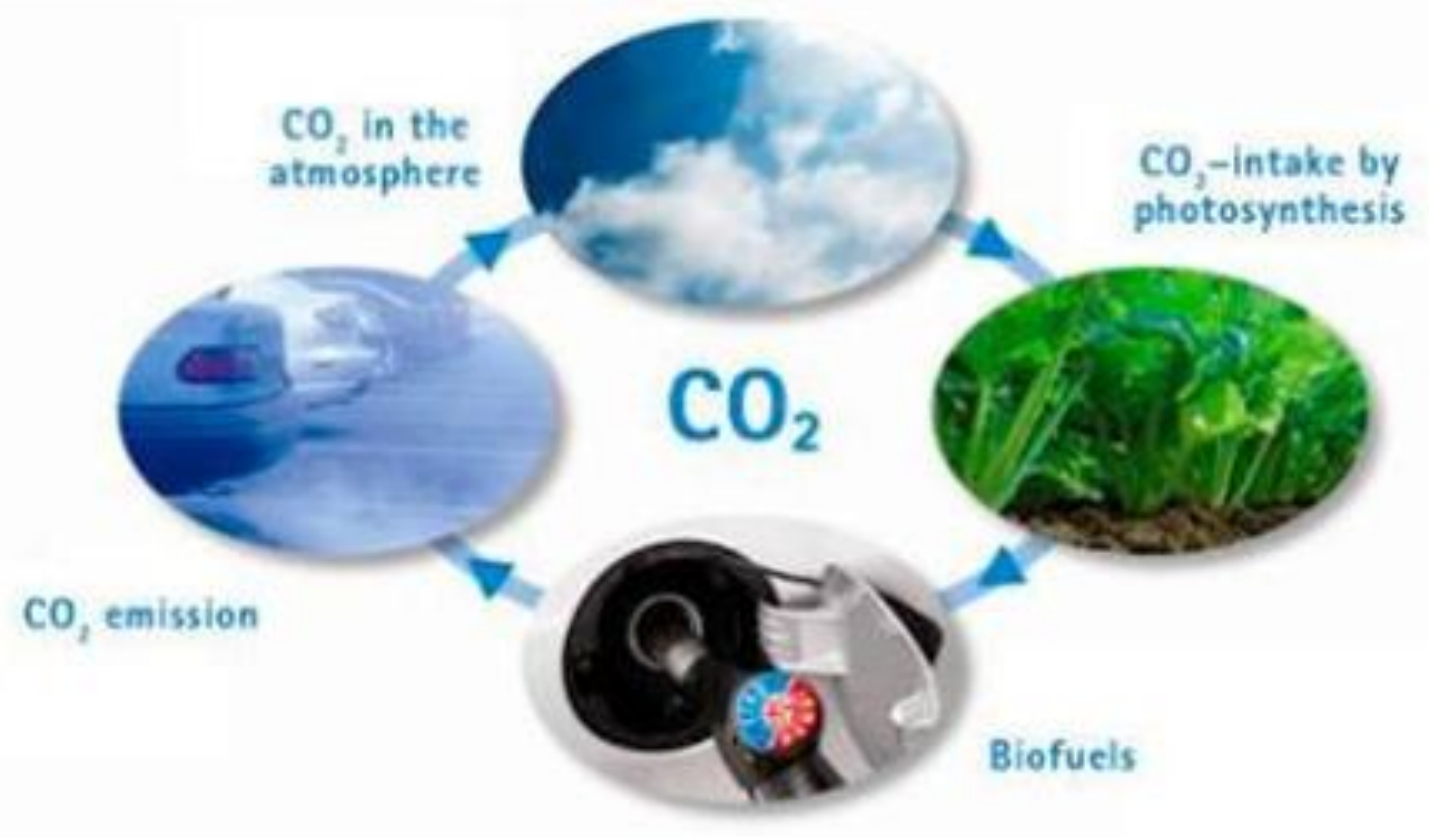


Fig.2 SHF with separate pentose and hexose sugars and combined sugar fermentation (Chandel, 2007)

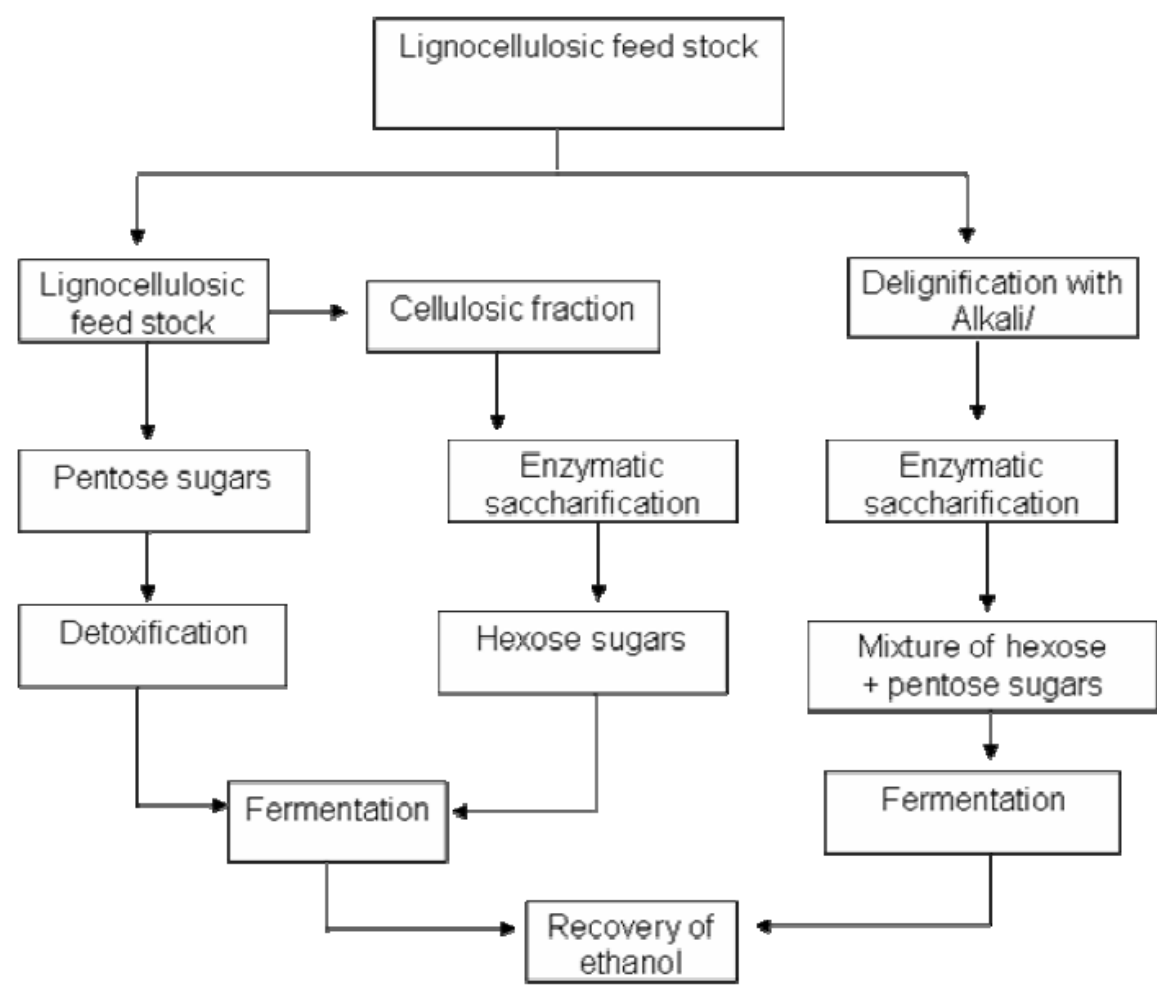

Fig.3 SSF with combined sugars (pentoses and hexoses) fermentation(Chandel, 2007).

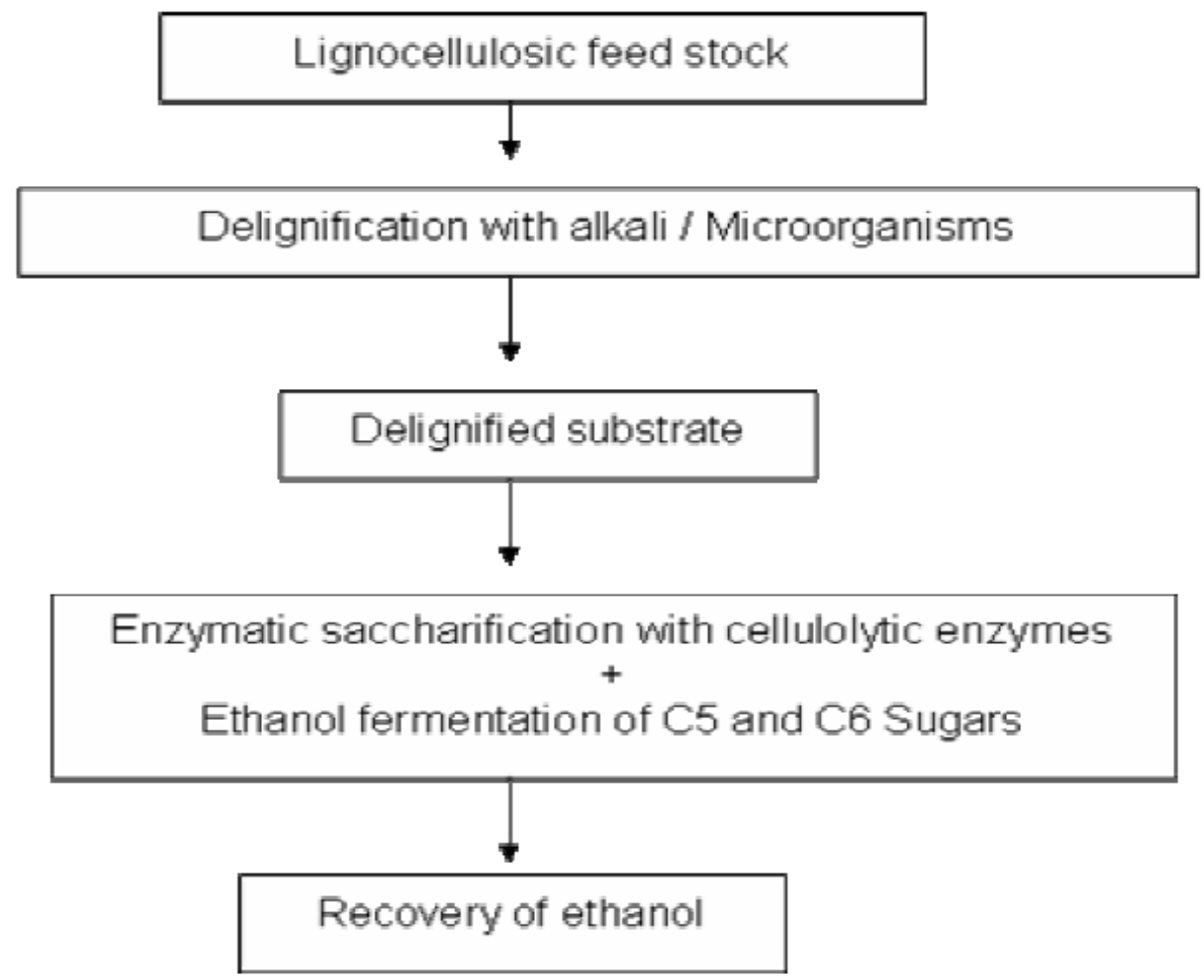


Fig.4 Percentage change in exhaust emissions in vegetable oil based biodiesels (Kralova and Sjöblom, 2010).

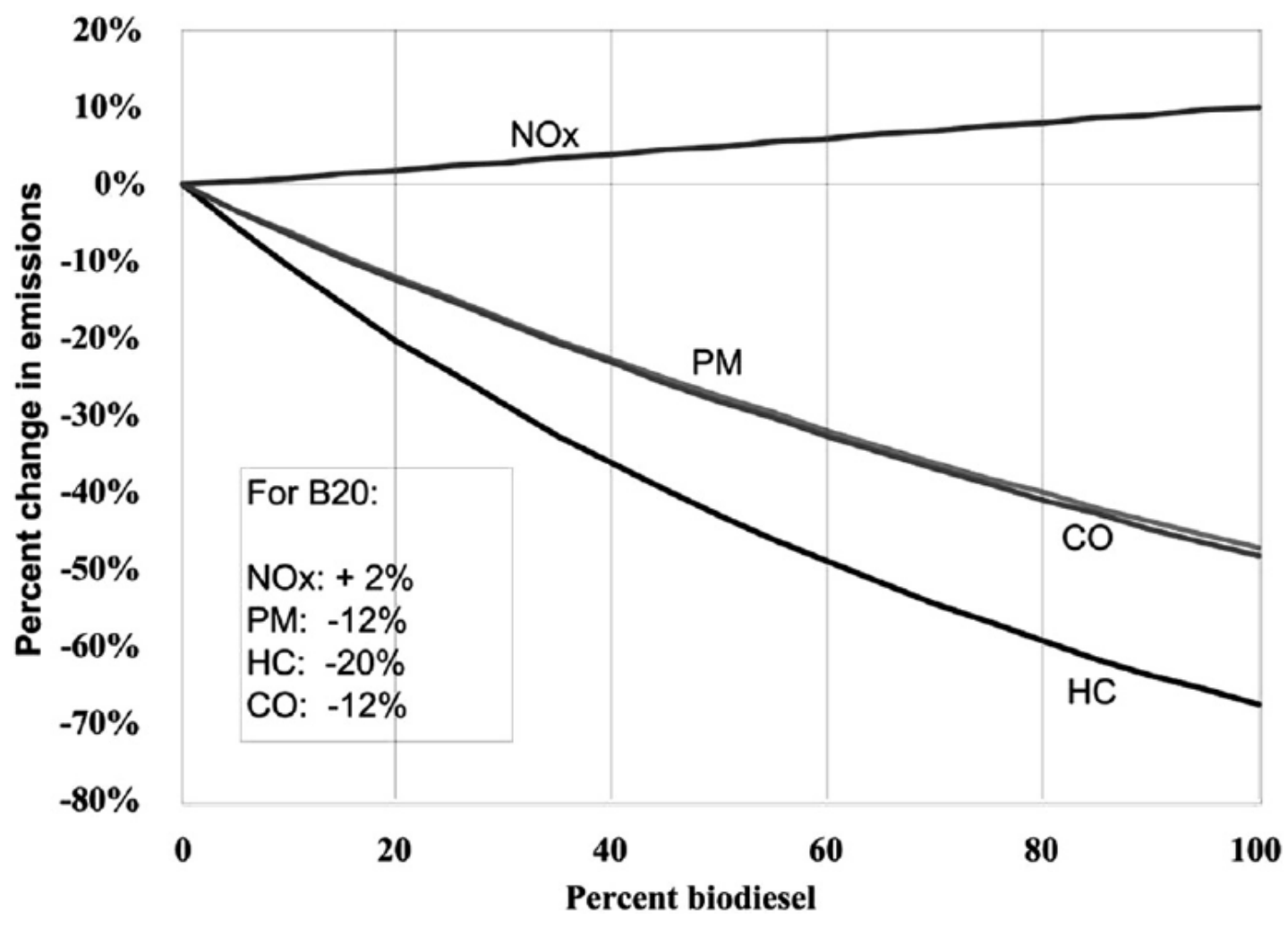

Figure 5: Scheme of the catalyzed transesterification of triglycerides to synthesize biodiesel (Bernal, 2012).
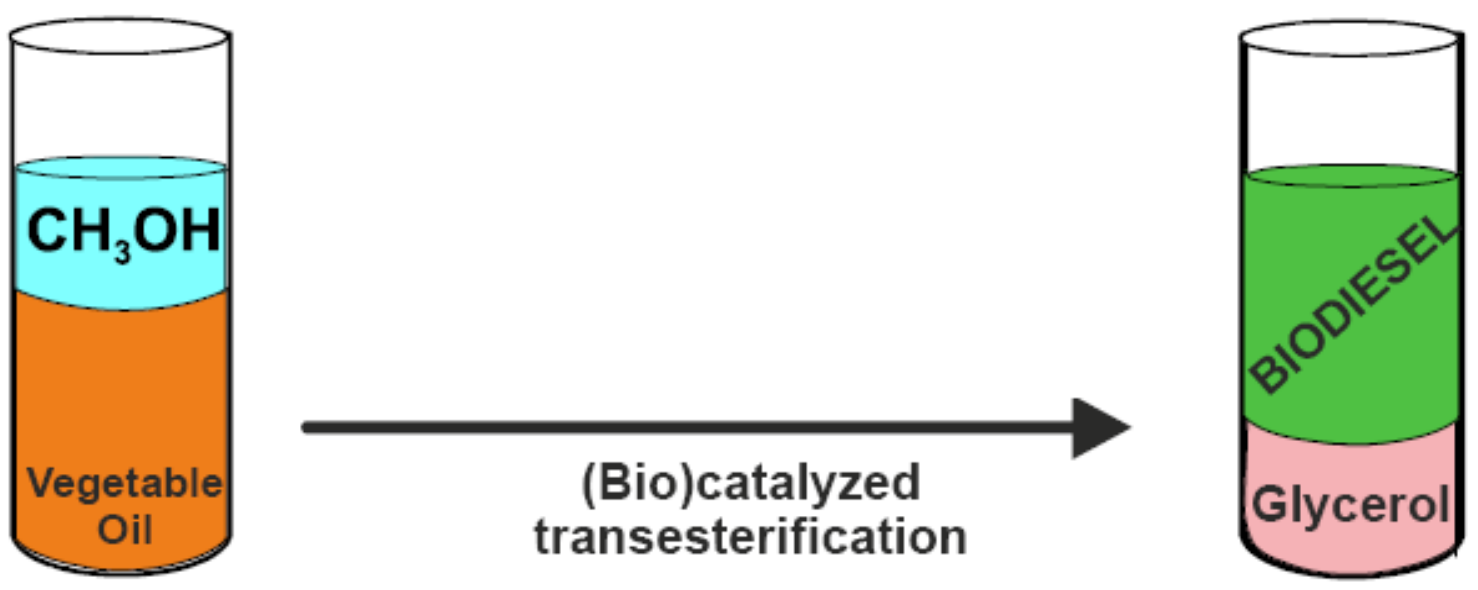
Equation.1 Chemical reaction of synthesis of biodiesel (Bajpai and Tyagi, 2006).

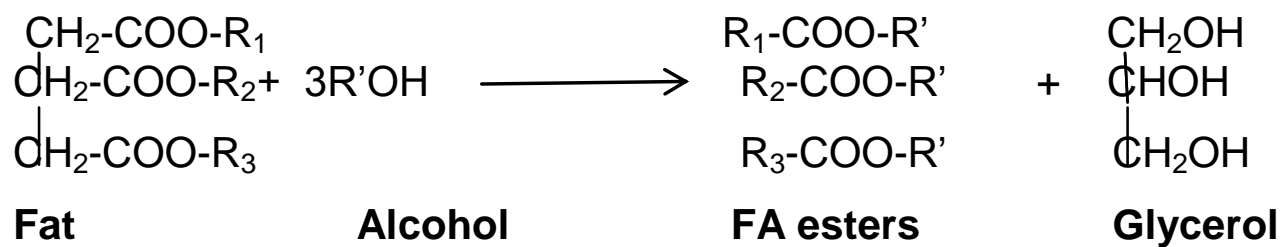

The basic catalyst is typically sodium hydroxide or potassium hydroxide. Recommended reaction time varies from 1 to 8 hours, and optimal reaction time is about 2 hours. Excess alcohol is normally used to ensure total conversion of the fat or oil into its esters. After the reaction is complete, two major products form: glycerin and biodiesel. The glycerin phase is much denser than the biodiesel (Figure 5) phase and the two can be gravity separated with glycerin simply drawn off the bottom of the settling vessel or by using a centrifuge separate the two materials faster.

The biodiesel product is sometimes purified by washing gently with warm water to remove residual catalyst or soaps, dried, and sent to storage (Kralova and Sjöblom, 2010).

When the free fatty acids (FFAs) content of the triglycerides is higher than $1-2 \% \mathrm{w} / \mathrm{w}$, basic catalysts can also produce saponification as a side reaction so the triglycerides and alcohol must be substantially anhydrous because water makes the reaction partially change to saponification, which produces soap that lowers the yield of esters and renders the separation of ester and glycerol difficult (Bernal, 2012; Kralova and Sjöblom, 2010).

\section{Enzyme Catalyzed Synthesis}

Enzymatic approaches for biodiesel production can generally be classified into whole cell- and lipase-mediated catalysis, which again can be subdivided into alcoholysis processes mediated by soluble or by immobilized lipases. Lipases play an important role in the metabolism of all living organisms. They can roughly be divided into intracellular and extracellular lipases and are easily obtained biotechnologically in high yields by fermentation and purification (Uthoff, 2009). Lipases are capable of catalyzing a variety of reactions such as hydrolysis, alcoholysis, esterification, transesterification, and hence are widely used in industry, so biodiesel can also be synthesized via lipase-catalyzed transesterification; the process produces high purity products and enables easy separation of the glycerol byproduct (Yu, 2013). Biodiesel synthesis by transesterification and/or esterification using immobilized lipase catalysis is applicable to both refined and raw plant oils, free fatty acids, waste fats from frying, tallow and other waste fats and it also requires less energy input due to lower reaction temperature than the base catalyzed process (Bernal, 2012).

The use of soluble lipases is advantageous because of the easy preparation process, but the enzyme is unstable and could be used only once due to its inactivation by the use of organic solvent in the synthesis process (Uthoff, 2009). This rises the costs of this process. In order to overcome the high cost, many studies propose the use of immobilized lipases that could be recovered easily after the synthesis ends and that have higher stability due to their binding to the support material.

There are many methods used for immobilization of lipases including: 
adsorptionof lipases by van der Waals or other weak forces to a special carrier material (acrylic resins, macro- and microporous resins, silica gels, hydrotalcite, celite), entrapment in which lipases are entrapped or encapsulated within a carrier matrix which confers more stability on the enzymes since thy are not subjected directly to shear forces (phyllosilicate sol-gel matrix), and cross linking techniques in which intermolecular crosslinks are formed by the reaction of multifunctional chemicals like glutaraldehyde or hexamethylened iisocyanate with enzyme molecules, yielding small aggregates that provide higher stability to the enzyme (Uthoff, 2009). Although these techniques overcome some problems associated with the use of soluble lipases, yet the enzymes are still prone to inactivation since methanol is insoluble in vegetable oils, so it inhibits the immobilized lipases and thereby decreases the catalytic activity of the transesterification reaction, and the hydrophilic by-product glycerol is also insoluble in the oil, so it is easily adsorbed onto the surface of the immobilized lipase leading to a negative effect on lipase activity and operational stability (Kumari, 2009). To overcome this problem, t-butanol could be used as a solvent since both methanol and glycerol are soluble in t- butanol, therefore the inhibitory effect of methanol and glycerol on lipase activity is reduced and t-butanol is not a substrate for the lipases because it does not act on tertiary alcohols (Kumari, 2009).

Another method used for biosynthesis of biodiesel whole-cell biocatalysts, such as filamentous fungi, yeast and bacteria. Filamentous fungi possess a great potential for biotechnological production of biodiesel due to their ability to synthesize intra- and extracellular lipases and lipase-producing fungi can be immobilized on biomass support particles (BSPs) and used as whole-cell biocatalyst which facilitates its reuse in other processes. Yeasts are attractive hosts for expression of membrane-bound lipases with an enhanced activity on cell surfaces for transesterification processes due to their eukaryotic expression mechanisms and bacteria-like growth and handling. Bacteria are often used as whole-cell biocatalysts in biotechnological production processes, because they can be cultivated to high cell densities and generally offer the possibility of genetic engineering (Uthoff, 2009).

Biofuels may be considered as a good alternative to fossil fuels due to their sustainability and less polluting emissions. However, many people argue that biofuels are doing more harm to the environment than fossil fuels. They claim that biofuels are posing danger on food resources available for people, causing deforestation and soil erosion, loss of biodiversity, and that they may be more polluting to the environment due to emission of aldehydes resulting from their combustion. Moreover, they argue that biofuel production is more time and money consuming and that it necessitates technical changes on car engines. But, the problems of food security and deforestation could be solved due to the new researches aiming to produce biofuels depending on microalgae and genetic engineering of microorganisms. Regarding the polluting effect, there are several contrasting studies. Some studies state that biofuels are environmentally friendly while others say that they are more harmful to the environment than fossil fuels. As for the technical issues, only minor changes are needed to be done on current engines for some types of biofuels whereas other types such as biodiesel can be used to run engines without any modification.

Many studies are being done and should be done in the future in order to reveal all the facts about biofuel industry and use in order to improve biofuel efficiency and reduce its potential harms. 


\section{References}

Bajpai, D., \&Tyagi, V. K. (2006). Biodiesel: source, production, composition, properties and its benefits. Journal of Oleo Science, 55(10), 487.

Bernal, J. M., Lozano, P., García-Verdugo, E., Burguete, M. I., Sánchez-Gómez, G., López-López, G., Pucheault, M., Vaultier, m., \& Luis, S. V. (2012). Supercritical synthesis of biodiesel. Molecules, 17(7), 8696-8719.

Carere, C. R., Sparling, R., Cicek, N., \& Levin, D. B. (2008). Third generation biofuels via direct cellulose fermentation. International journal of molecular sciences, 9(7), 1342-1360.

Chandel, A. K., Chan, E. S., Rudravaram, R., Narasu, M. L., Rao, L. V., \&Ravindra, P. (2007). Economics and environmental impact of bioethanol production technologies: an appraisal. Biotechnology and Molecular Biology Review, 2(1), 14-32.

Deenanath, E. D., Iyuke, S., \&Rumbold, K. (2012). The bioethanol industry in subSaharan Africa: history, challenges, and prospects. BioMed Research International, 2012.

Dellomonaco, C., Fava, F., \& Gonzalez, R. (2010). The path to next generation biofuels: successes and challenges in the era of synthetic biology. Microb Cell Fact, 9(3), 1-15.

Giampietro, M., Ulgiati, S., \& Pimentel, D. (1997). Feasibility of large-scale biofuel production. BioScience, 47(9),
587-600.

Goldemberg, J. (2008). The Brazilian biofuels industry. Biotechnology for biofuels, 1(6), 1-7.

Kralova, I., \&Sjöblom, J. (2010). Biofuelsrenewable energy sources: a review. Journal of Dispersion Science and Technology, 31(3), 409-425.

Kumari, A., Mahapatra, P., Garlapati, V. K., \&Banerjee, R. (2009). Enzymatic transesterification of Jatropha oil. Biotechnol Biofuels, 2(1), 1-6.

Lennen, R. M., \&Pfleger, B. F. (2012). Engineering Escherichia coli to synthesize free fatty acids. Trends in biotechnology, 30(12), 659-667.

Uthoff, S., Bröker, D., \&Steinbüchel, A. (2009). Current state and perspectives of producing biodiesel-like compounds by biotechnology. Microbial biotechnology, 2(5), 551-565.

Wackett, L. P. (2008). Microbial-based motor fuels: science and technology. Microbial Biotechnology, 1(3), 211225.

Yu, C. Y., Huang, L. Y., Kuan, I., \& Lee, S. L. (2013). Optimized Production of Biodiesel from Waste Cooking Oil by Lipase Immobilized on Magnetic Nanoparticles. International journal of molecular sciences, 14(12), 2407424086.

http://www.bdbe.de/. Retrieved: April 12, 2014.

\section{How to cite this article:}

Sami El Khatib and Nejma Abou Yassin 2019. Advances in Synthetic Biology and Metabolic Engineering in the Production of Biofuel. Int.J.Curr.Microbiol.App.Sci. 8(09): 1762-1772. doi: https://doi.org/10.20546/ijcmas.2019.809.204 